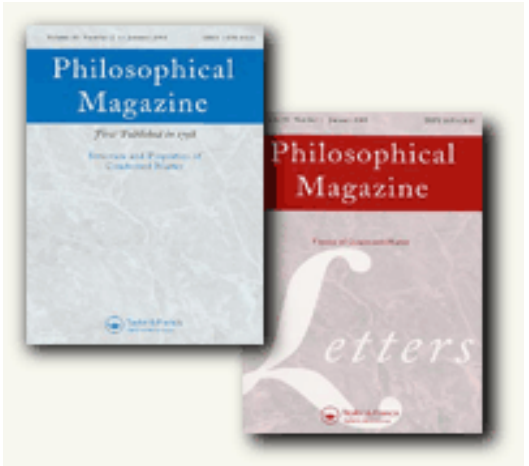

\title{
A case study of complex metallic alloy phases: Structure and disorder phenomena of Mg-Pd compounds
}

\begin{tabular}{|r|l|}
\hline Journal: & Philosophical Magazine \& Philosophical Magazine Letters \\
\hline Manuscript ID: & TPHM-05-May-0226.R1 \\
\hline Journal Selection: & Philosophical Magazine \\
\hline Date Submitted by the & 03-Jul-2005 \\
\hline Complete List of Authors: & $\begin{array}{l}\text { Makongo, Julien; Max-Planck-Institut für Chemsiche Physik fester } \\
\text { Stoffe } \\
\text { Prots, Yurii; Max-Planck-Institut für Chemische Physik fester Stoffe } \\
\text { Burkhardt, Ulrich; Max-Planck-Institut für Chemsiche Physik fester } \\
\text { Stoffe } \\
\text { Niewa, Rainer; Max-Planck-Institut für Chemsiche Physik fester } \\
\text { Stoffe; Max-Planck-Institut für Chemische Physik fester Stoffe } \\
\text { Kudla, Christian; Max-Planck-Institut für Chemsiche Physik fester } \\
\text { Stoffe } \\
\text { Kreiner, Guido; Max-Planck-Institut für Chemische Physik fester } \\
\text { Stoffe }\end{array}$ \\
\hline Keywords: & phase diagrams, Mg alloys, crystal structure, crystal defects \\
\hline Keywords (user supplied): & \begin{tabular}{l} 
Pd, intermetallic phases \\
\hline
\end{tabular} \\
\hline
\end{tabular}

\section{S ScholaroNE" Manuscript Central}




\title{
A case study of complex metallic alloy phases: Structure and disorder phenomena of Mg-Pd compounds
}

\author{
Julien Pierre Amelie MaKongo, YuriI Prots, UlRich BurkHARdt, RAINER NIEWA \\ CHRISTIAN KUDLA and GUIDO KREINER* \\ Max-Planck-Institut für Chemische Physik fester Stoffe, Nöthnitzer Str. 40, D-01187 Dresden, Germany
}

\begin{abstract}
In order to achieve a deeper insight into the relation between the homogeneity range, crystal structure and disorder phenomena of complex metallic alloy phases (CMAs) we have re-determined the Mg-Pd phase diagram in the range 60 to 100 at- $\% \mathrm{Mg}$. The existence of the intermediate phases $\mathrm{Mg}_{6} \mathrm{Pd}(\beta), \mathrm{Mg}_{57} \mathrm{Pd}_{13}(\gamma), \mathrm{Mg}_{56.4} \mathrm{Pd}_{13.5}(\delta), \mathrm{Mg}_{306} \mathrm{Pd}_{77}(\varepsilon), \mathrm{Mg}_{78.5} \mathrm{Pd}_{21.5}$ $(\zeta), \mathrm{Mg}_{3} \mathrm{Pd}(\eta), \mathrm{Mg}_{5} \mathrm{Pd}_{2}(\theta)$ and $\mathrm{Mg}_{2} \mathrm{Pd}(\mathrm{l})$ has been reconfirmed. The first five of them are CMA's. The $\beta$-phase melts congruently whereas the CMAs $\gamma, \delta, \varepsilon$ and $\zeta$ form in a cascade of peritectoid and peritectic reactions in a narrow window of approx. $30^{\circ} \mathrm{C}$ and 3 at- $\%$. It is assumed that the stability of the Mackay icosahedron plays an important role in the phase formation of these CMA's. However, the $\beta$-phase reveals an intricate pattern of disorder at the atomic positions of the Mackay icosahedron (MI). Therefore, the concept of the stability of the Mackay cluster should be used only as a rule of thumb.
\end{abstract}

\section{Introduction}

Complexity in the sense of giant unit cells and inherent structural disorder is one of the most pronounced features of complex metallic alloy phases (CMAs). Prominent examples of CMAs are approximant phases of icosahedral quasicrystals with the Mackay cluster as fundamental structural unit. Recently, we reported on the synthesis and crystal structure of Mg-rich complex alloys in the binary $\mathrm{Mg}$-Pd system [1]: $\mathrm{Mg}_{6} \mathrm{Pd}(\beta), \mathrm{Mg}_{57} \mathrm{Pd}_{13}(\gamma)$, $\mathrm{Mg}_{56.4} \mathrm{Pd}_{13.5}(\delta), \mathrm{Mg}_{306} \mathrm{Pd}_{77}(\varepsilon), \mathrm{Mg}_{78.5} \mathrm{Pd}_{21.5}(\zeta), \mathrm{Mg}_{3} \mathrm{Pd}(\eta), \mathrm{Mg}_{5} \mathrm{Pd}_{2}(\theta)$ and $\mathrm{Mg}_{2} \mathrm{Pd}(\mathrm{l})$. The first five intermetallic compounds are CMAs of the Mackay cluster type with giant unit cells containing several hundred atoms. In order to achieve a deeper insight into the relation between the homogeneity range, crystal structure and disorder phenomena in the CMAs we have determined the extent of the single-phase fields for the above listed phases by chemical, metallographic, thermal and X-ray powder and single crystal analyses. The current results of a re-determination of the $\mathrm{Mg}$-rich part of the phase diagram are presented. For $\mathrm{Mg}_{6} \mathrm{Pd}$ the origin of the homogeneity range is discussed in more detail.

\section{Experimental}

Samples of the nominal composition $\operatorname{Mg}_{\mathrm{x}} \mathrm{Pd}_{1-\mathrm{x}}$ with $0.6 \leq x<1$ in steps of approx. 0.01 were prepared by induction melting mixtures of the elements (Pd, 99.99\%; $\mathrm{Mg}, 99.99 \%)$ in argon filled and weld-sealed tantalum ampoules. Subsequently, the ampoules were encapsulated in

\footnotetext{
*Email: kreiner@cpfs.mpg.de
} 
fused silica tubes and annealed several weeks at appropriate temperatures. Finally, the ampoules were quenched in water.

Chemical analyses on impurities of $\mathrm{O}, \mathrm{N}, \mathrm{C}, \mathrm{H}$ and Ta were carried out using carrier gas hot extraction, the combustion technique and ICP-MS spectroscopy, respectively. All impurities were below their respective limit of detection. The microstructures of the samples were analyzed via microscopic examination in combination with EDXS to determine the number of phases and their compositions. For single phase materials, the $\mathrm{Mg}$ and $\mathrm{Pd}$ content was analyzed by atomic emission spectrometry with plasma excitation (ICP-OES). The deviations between the nominal and the experimental determined compositions were smaller than 0.1 at- $\%$.

The unit cell parameters of the phases were obtained from least-squares fits of Guinier powder data with $\mathrm{CuK} \alpha_{1}$ radiation and internal calibration. X-ray powder diffraction patterns for Rietveld refinements were collected on a diffractometer in Bragg-Brentano geometry and single crystal data on a CCD diffractometer with MoK $\alpha$ radiation.

DTA and DSC measurements were carried out to determine the liquidus and the solidus curves as well as the temperatures of the invariant reactions with the samples weld-sealed in $\mathrm{Nb}$ crucibles under dry argon.

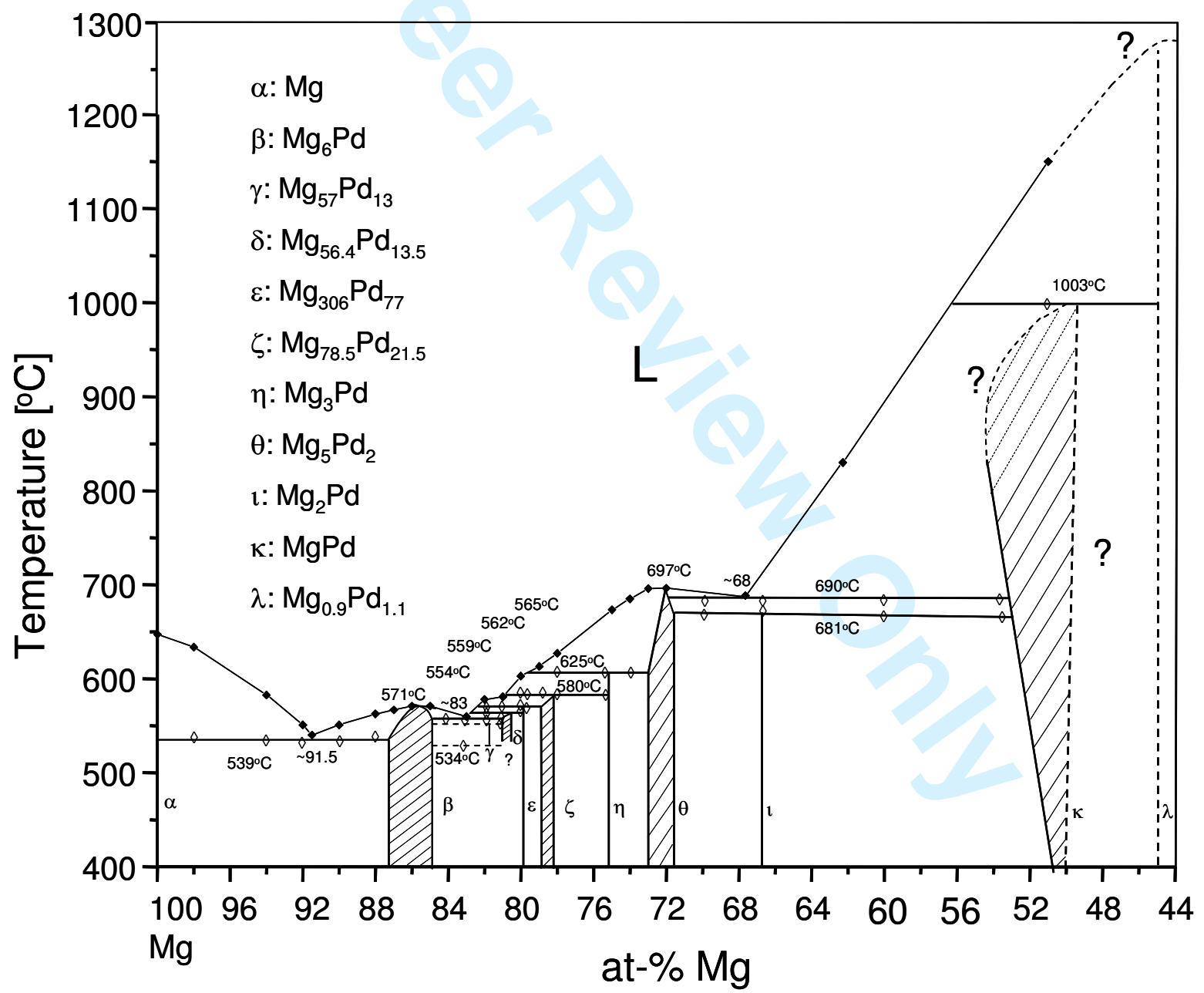

Figure 1. The Mg-rich part (44-100 at-\% Mg) of the Mg-Pd phase diagram according to data of this study; only data points obtained from thermal analysis measurements are shown in the graph; question marks and dashed lines indicate unresolved problems; phase labels are located in the Pd-rich two-phase fields. 

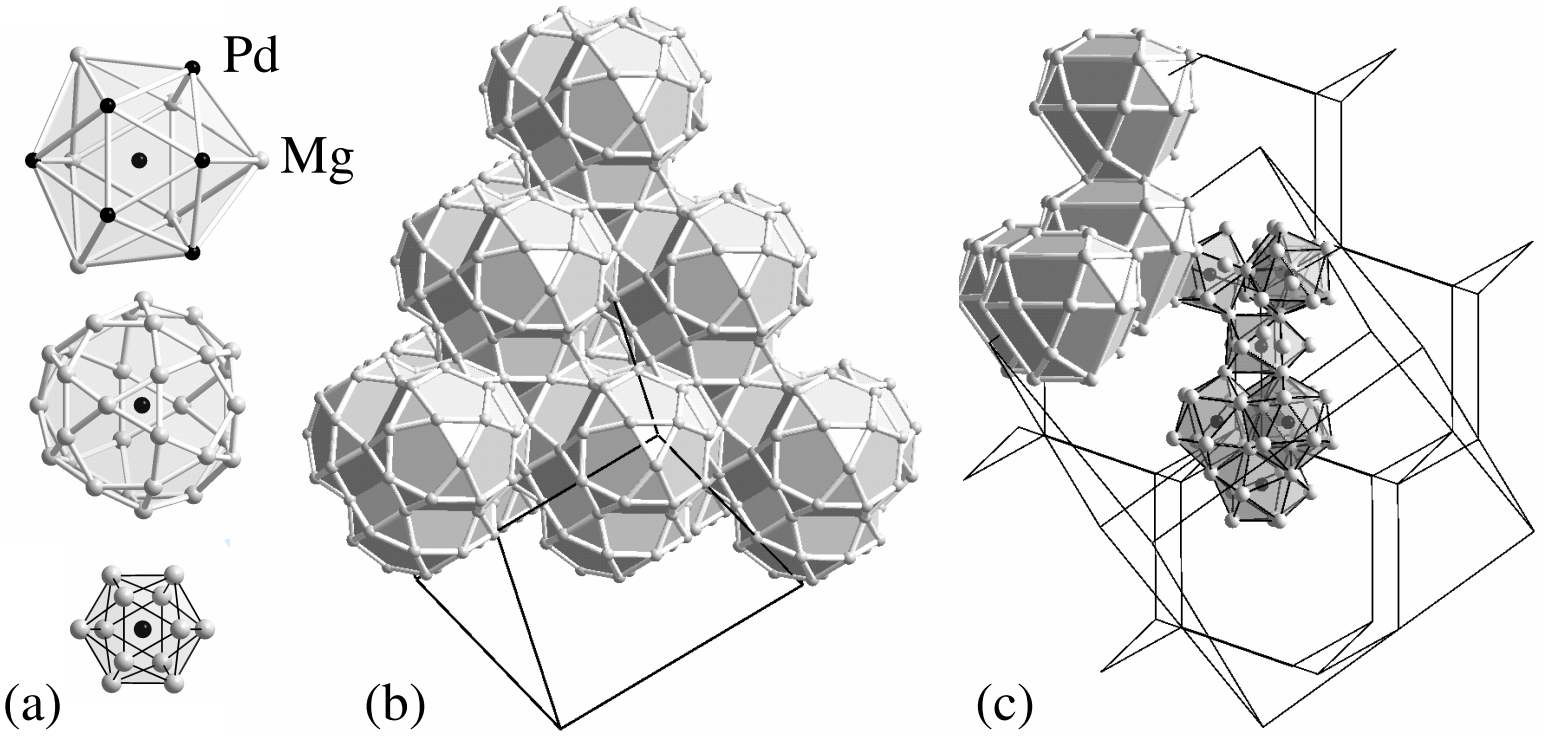

Figure 2. $\mathrm{Mg}_{6} \mathrm{Pd}$ : a) Concentric shell structure of the MI. b) Packing of the MIs with interpenetrating and pentagonal face-sharing MIs. c) Arrangement of the remaining space-filling polyhedra at the nodes of a diamond net.

\section{Results}

The revised Mg-rich part of the phase diagram is shown in figure $1 . \mathrm{Mg}_{6} \mathrm{Pd}(\beta)$ has the highest $\mathrm{Mg}$ content of all intermediate phases in the $\mathrm{Mg}-\mathrm{Pd}$ system with a range of homogeneity extending from $87.4(1)$ to $85.0(1)$ at- $\% \mathrm{Mg}$ at $530(5){ }^{\circ} \mathrm{C} . \mathrm{Mg}_{6} \mathrm{Pd}$ melts congruently at 571(3) ${ }^{\circ} \mathrm{C}$ and forms eutectic alloys with $\mathrm{Mg}(\alpha)$ at $91.5(5)$ at- $\% \mathrm{Mg}$ and $\operatorname{Mg}_{56.4} \operatorname{Pd}_{13.5}(\delta)$ at 83(1) at- $\% \mathrm{Mg}$. The eutectic temperatures are 539(3) ${ }^{\circ} \mathrm{C}$ and 559(3) ${ }^{\circ} \mathrm{C}$, respectively.

Close to 80 at- $\% \mathrm{Mg}$ the CMAs $\gamma, \delta, \varepsilon$ and $\zeta$ were observed. $\operatorname{Mg}_{57} \operatorname{Pd}_{13}(\gamma)$ crystallizes with no perceptible homogeneity range at $81.4(1)$ at- $\% \mathrm{Mg}$. The $\gamma$-phase undergoes a peritectoid $(\beta+\delta=\gamma)$ and a eutectoid $(\gamma=\beta+\varepsilon)$ reaction at $554(3){ }^{\circ} \mathrm{C}$ and $534(5){ }^{\circ} \mathrm{C}$, respectively. $\mathrm{Mg}_{56.4} \mathrm{Pd}_{13.5}(\delta)$ forms peritectically $(\mathrm{L}+\varepsilon=\delta)$ at $562(3){ }^{\circ} \mathrm{C}$ and $80.7(3)$ at $-\%$ $\mathrm{Mg}$ with a small homogeneity range of about 0.3 at $\%$. Presently, sufficient data to define the $\delta$ phase boundaries at lower temperatures are not available. $\operatorname{Mg}_{306} \mathrm{Pd}_{77}(\varepsilon)$, forms peritectically at $565(3){ }^{\circ} \mathrm{C}(\mathrm{L}+\zeta=\varepsilon)$ with no perceptible homogeneity range at 79.9(1) at-\% Mg. Finally, the $\zeta$-phase extends from $78.8(2)$ to $78.3(2)$ at- $\% \mathrm{Mg}$ at $500(5){ }^{\circ} \mathrm{C}$ and undergoes a peritectic reaction at $580(3){ }^{\circ} \mathrm{C}(\mathrm{L}+\eta=\zeta)$. Due to its unknown crystal structure a crystallographic formula can not be assigned. However, a preliminary study supports that the crystal structure of the $\zeta$-phase is built up from Mackay clusters.

$\eta, \theta$ and $\imath$ are no CMA's. $\mathrm{Mg}_{3} \mathrm{Pd}(\eta)$ crystallizes with no perceptible homogeneity range at $75.0(1)$ at- $\% \mathrm{Mg}$ and forms in a peritectic reaction $(\mathrm{L}+\theta=\eta)$ at $625(3){ }^{\circ} \mathrm{C} . \mathrm{Mg}_{5} \mathrm{Pd}_{2}$ $(\theta)$ exhibits a small homogeneity range extending from $72.7(1)$ to $71.4(1)$ at $-\% \mathrm{Mg}$ at 500(5) ${ }^{\circ} \mathrm{C} . \mathrm{Mg}_{5} \mathrm{Pd}_{2}$ melts congruently at $697(3){ }^{\circ} \mathrm{C}$ and forms an eutectic alloy with $\mathrm{MgPd}(\kappa)$ at approx. 68(2) at- $\% \mathrm{Mg}$ and at $690(3){ }^{\circ} \mathrm{C}$. Finally, $\mathrm{Mg}_{2} \mathrm{Pd}$ (1) crystallizes with no perceptible homogeneity range at $66.7(1)$ at- $\% \mathrm{Mg}$ and undergoes a peritectoid reaction $(\theta+\kappa=1)$ at 681(3) ${ }^{\circ} \mathrm{C}$.

To study the origin of the homogeneity range of $\mathrm{Mg}_{6} \mathrm{Pd}$ including disorder phenomena, its crystal structure has been investigated in more detail. $\mathrm{Mg}_{6} \mathrm{Pd}$ crystallizes [2] with a large face-centred cubic unit cell in the space group $F-43 m$. The unit cell parameter $a$ decreases linearly from 20.1985(6) $\AA$ at the Mg-rich limit to 20.045(5) $\AA$ at the Pd-rich limit. 
(a)

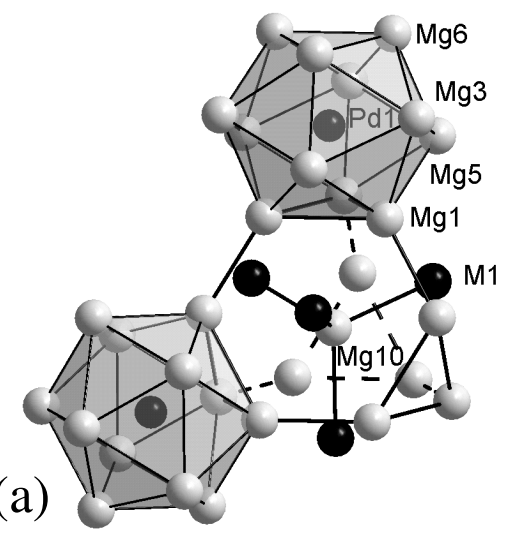

(b)
$\mathrm{Mg}_{87.4} \mathrm{Pd}_{12.6} \quad \mathrm{Mg}_{86.7} \mathrm{Pd}_{13.3} \quad \mathrm{Mg}_{85.0} \mathrm{Pd}_{15.0}$
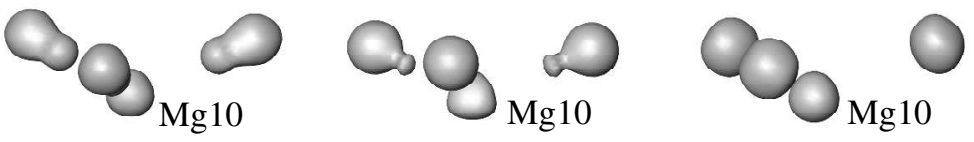

M1

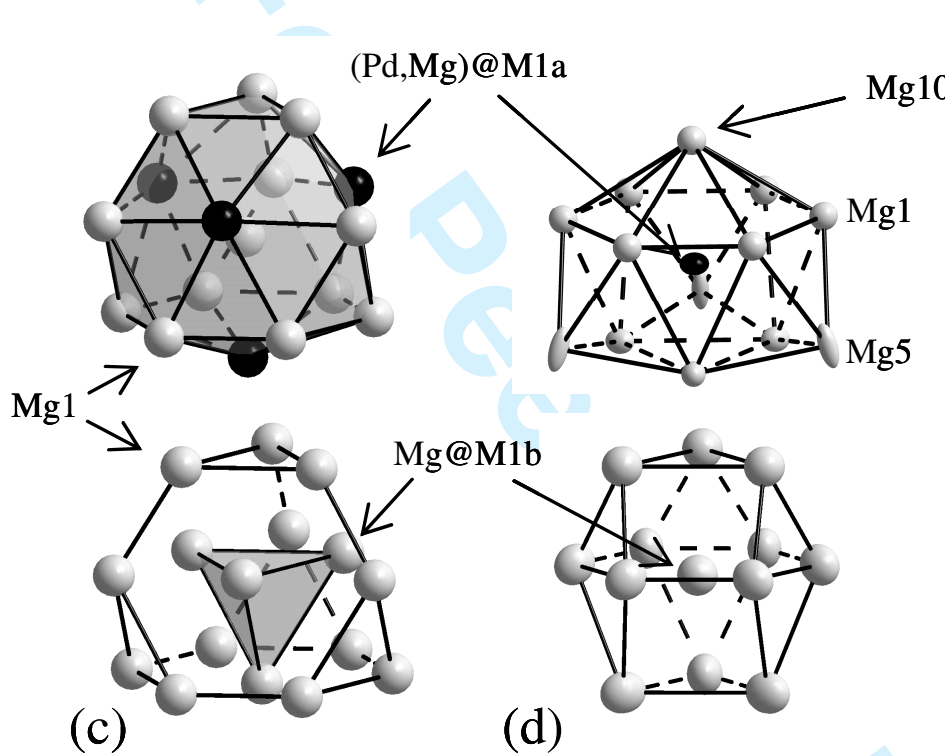

(e)
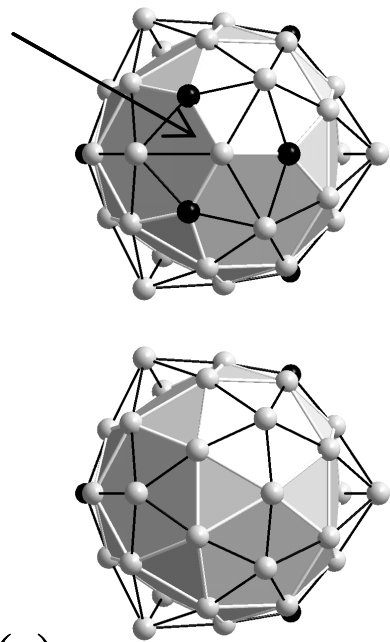

Figure 3. Point defects in the crystal structure of $\mathrm{Mg}_{6} \mathrm{Pd}$ : a) Four inner icosahedra of pentagonal facesharing MIs form a truncated tetrahedron with $\mathrm{Mg} 1$ at the vertices, $\mathrm{Mg} 10$ at the centre and $\mathrm{M} 1$ capping the four hexagons; for clarity two icosahedra are omitted. b) Isosurfaces of the electron density $\left(4 \mathrm{e} / \AA^{3}\right)$ at $\mathrm{M} 1$ and $\mathrm{Mg} 10$ for $\mathrm{Mg}_{6} \mathrm{Pd}$ at 87.4 at- $\%, 86.7$ at-\% and 85.0 at-\% $\mathrm{Mg}$ obtained from X-ray single crystal structure refinements. c-e) Selected polyhedra in the crystal structure of $\mathrm{Mg}_{6} \mathrm{Pd}$ at the Pd-rich limit (top row) and Mg-rich limit (bottom row). c) Z16 Frank-Kasper polyhedron and $\mathrm{Mg}_{4}$ stuffed truncated tetrahedron. d) Coordination type polyhedra of M1a and M1b. e) modified and nearly perfect MI.

The crystal structure is conveniently described as an arrangement of interpenetrating and pentagonal face-sharing distorted Mackay icosahedra (MI) as shown in figure $2 \mathrm{~b}$. The concentric shells of the MI are shown in figure 2a neglecting any kind of disorder: $12 \mathrm{Mg}$ at the vertices of the inner icosahedron with $\mathrm{Pd}$ at the centre, $30 \mathrm{Mg}$ at the vertices of the icosidodecahedron and $6 \mathrm{Mg}$ plus $6 \mathrm{Pd}$ at vertices of the outer icosahedron. The large voids of the MI packing are filled by polyhedra bounded by $24 \mathrm{Mg}$ atoms. The polyhedra are arranged at the positions of a diamond net as shown in figure 2c. Half of the polyhedra contain tetrahedral units of face-sharing $\mathrm{PdMg}_{12}$ icosahedra. This building block is commonly known as a Pearce cluster. The remaining space-filling polyhedra contain tetrahedral units of four $\mathrm{PdMg}_{9}$ tri-capped trigonal prisms.

Four of the 14 crystallographic sites of $\mathrm{Mg}_{6} \mathrm{Pd}$ are influenced by disorder. The positions of the defect sites $\mathrm{M} 1, \mathrm{Mg} 1, \mathrm{Mg} 5$, and $\mathrm{Mg} 10$ are shown in figure 3a. Here, the inner icosahedra of four MIs form a truncated tetrahedron with $\mathrm{Mg} 1$ at the vertices. For clarity two of the icosahedra as well as all surrounding icosidodecahedral shells are omitted. The 
truncated tetrahedron is occupied at the centre by $\mathrm{Mg} 10$ and its hexagon faces are capped by $\mathrm{M} 1 . \mathrm{Mg} 5$ is located at the vertices of the inner icosahedra adjacent to Mg1.

Isosurfaces obtained from X-ray single crystal structure refinements of the electron density at $\mathrm{M} 1$ and $\mathrm{Mg} 10$ for $\mathrm{Mg}_{6} \mathrm{Pd}$ at 87.4 at- $\%, 86.7$ at- $\%$ and 85.0 at- $\% \mathrm{Mg}$ are shown in figure 3b. At the Mg-rich limit the M1 site reveals an electron density distribution corresponding to an atomic split position. M1a is occupied by $\mathrm{Pd}$ or $\mathrm{Mg}$ and M1b by Mg. The following restraints for the site occupancy factors (s.o.f.) of M1a, M1b and Mg10 have been introduced in the refinement to avoid non-physical short interatomic distances: s.o.f.(Pd@M1a) + s.o.f.(Mg@M1a) + s.o.f.(Mg@M1b) = 1 and s.o.f.(Mg@M1b) + s.o.f. $(\mathrm{Mg} 10)=1$. A higher $\mathrm{Pd}$ content in $\mathrm{Mg}_{6} \mathrm{Pd}$ increases and reduces the observed electron densities at M1a and M1b, respectively. At the Pd-rich phase limit the density at M1b disappears. However, the density at Mg10 increases until the position is fully occupied by $\mathrm{Mg}$. Constitutional vacancies appear simultaneously at the $\mathrm{Mg} 1$ site in combination with a large anisotropic displacement of Mg5.

An interpretation of the observed electron density at the defect sites of $\mathrm{Mg}_{6} \mathrm{Pd}$ is as follows. At the Pd-rich phase boundary the atomic environment of Mg10 is a Frank-Kasper Z16 coordination type polyhedron with maximal two vacancies at the $\mathrm{Mg} 1$ positions as shown in figure 3c. The centre of the Z16 is fully occupied by $\mathrm{Mg}$ whereas the hexagon caps are randomly mixed occupied by $\mathrm{Pd}$ and $\mathrm{Mg}$. The $\mathrm{M} 1$ site is maximal surrounded by $13 \mathrm{Mg}$ atoms (figure $3 \mathrm{~d}$ ). In case of Pd at M1 a vacancy in the neighbourhood yields the coordination number 12. The displacement of Mg5 shortens the interatomic distances between Pd and three Mg5 atoms. A vacancy at $\mathrm{Mg} 1$ creates a truncated inner icosahedron whereas the icosidodecahedral shell is modified by inserting a $\mathrm{Mg} 10$ atom slightly above a triangular face as shown in figure $3 \mathrm{e}$.

Part of the excess $\mathrm{Mg}$ in the crystal structure of $\mathrm{Mg}_{6} \mathrm{Pd}$ occupies the M1a site. The higher percentage of $\mathrm{Mg}$ at $\mathrm{M} 1 \mathrm{a}$ minimizes the number of vacancies at $\mathrm{Mg} 1$ and the number of displaced Mg5 atoms. However, some of the excess Mg occupies the additional M1b site. In that case an occupation of the neighbouring M1a and Mg10 is due to short non-physical interatomic distances forbidden. Here, the most likely scenario is a simultaneous occupation of the four M1b positions by $\mathrm{Mg}$ per truncated tetrahedron. The truncated tetrahedron forms with the $\mathrm{Mg}_{4}$ tetrahedron together a structural unit which is e.g. part of the crystal structure of $h c p-\mathrm{Mg}$. Moreover, the icosidodecahedral shells of the surrounding MIs are then nearly perfect. The coordination type polyhedron of $\mathrm{Mg}$ at M1b is an anti-cuboctahedon formed by $12 \mathrm{Mg}$ atoms. From a geometrical point of view the occupation of $\mathrm{Mg}$ at $\mathrm{M} 1 \mathrm{~b}$ seems to be the "natural decoration" for $\mathrm{Mg}_{6} \mathrm{Pd}$ resulting in the formula $\mathrm{Mg}_{43} \mathrm{Pd}_{6}(Z=8,87.8$ at- $\% \mathrm{Mg})$. However, in the crystal structure of $\mathrm{Mg}$-rich $\mathrm{Mg}_{6} \mathrm{Pd}$ about $1 / 3$ of the truncated tetrahedra are decorated with $\mathrm{Mg}_{4}$ tetrahedra and the remaining 2/3 with $\left(\mathrm{Pd}_{\mathrm{x}} \mathrm{Mg}_{1-\mathrm{x}}\right)_{4} \mathrm{Mg}$ units similar as found in the crystal structure at the Pd-rich limit.

\section{Conclusion}

The re-determination of the $\mathrm{Mg}$-rich part of the $\mathrm{Mg}$-Pd phase diagram reconfirmed the existence of the intermediate phases $\beta, \gamma, \delta, \varepsilon, \zeta, \eta, \theta$, and . Close to 80 at- $\% \mathrm{Mg}$ the CMAs $\gamma, \delta, \varepsilon$ and $\zeta$ form in a cascade of peritectoid and peritectic reactions in a small range of temperature $\left(\sim 30{ }^{\circ} \mathrm{C}\right)$ and composition $(\sim 3$ at- $\%)$. It is to assume that the stability of the fundamental structural unit, i.e. the Mackay cluster, plays an important role in the phase formation. From the crystal structures and the narrow regions of homogeneity of $\mathrm{Mg}_{57} \mathrm{Pd}_{13}$ $(\gamma), \mathrm{Mg}_{56.4} \mathrm{Pd}_{13.5}(\delta)$, and $\mathrm{Mg}_{306} \mathrm{Pd}_{77}(\varepsilon)$ it can be shown that a small variation of about 1 at $\%$ in the $\mathrm{Mg}$ concentration yields a much higher percentage of variation in the "glue atoms" region inducing a rearrangement of the cluster packing. From this point of view an 
accumulation of CMA's of nearly equal composition is understandable. However, the results of the origin of the homogeneity range of $\mathrm{Mg}_{6} \mathrm{Pd}$ advice caution. Here, the Mackay cluster shows an extremely high degree of disorder. Therefore, the stability of the Mackay cluster should be used only as a rule of thumb. Due to the many degrees of freedom for CMA's, extrapolations even for such a tiny homogeneity range of 2.4 at- $\%$ as found in $\mathrm{Mg}_{6} \mathrm{Pd}$ are not allowed.

\section{Acknowledgements}

The authors wish to acknowledge support by Dr. G. Auffermann, A. Völzke, U. Schmidt (chemical analyses), Dr. M. Boström (synthesis) S. Müller (thermal analysis), Dr. R. Ramlau, K. Schulze (SEM/EDXS), Dr. R. Cardoso, and S. Hückmann (X-ray powder diffraction). We are also deeply indebted to Dr. A. Leithe-Jasper, Prof. Dr. R. Kniep and Prof. Dr Y. Grin whose detailed comments have helped us substantially.

\section{References}

[1] J.P.A. Makongo, Yu. Moguilnikov, C. Kudla, D. Grüner, M. Schäpers, G. Kreiner, Mat. Res. Soc. Symp. Proc., 805 LL2.1.1 (2004).

[2] S. Samson, Acta Crystallogr. B 28936 (1972). 